\title{
A Report of Two Cases with Different Clinical Presentation of Cerebral Toxoplasmosis in HIV-Infected Bulgarian Patients
}

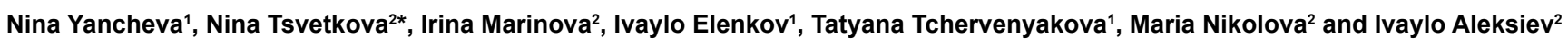

${ }^{1}$ AIDS Department, Specialized Hospital for Infectious and Parasitic Diseases, Medical University, Sofia, Bulgaria

${ }^{2}$ National Reference Laboratory of Parasitology, National Institute of Infectious and Parasitic Diseases, Sofia, Bulgaria

\begin{abstract}
Toxoplasmosis is a disease caused by an obligate intracellular protozoan Toxoplasma gondii. In immunocompetent adults, infection can occur subclinically, or with lymphadenitis. In HIV-infected individuals with severe immune suppression, Toxoplasma gondii can cause severe disease with invasion of the gray and white matter of the brain, the retina, the lungs, the heart and the skeletal muscles. Toxoplasmosis is the most common opportunistic infection of the central nervous system in patients with acquired immunodeficiency syndrome (AIDS). The clinical presentation of cerebral toxoplasmosis in the majority of these patients includes headaches, focal neurological deficits, and seizures. In this article, we report two cases with different presentation of cerebral toxoplasmosis in the setting of an HIV infection.
\end{abstract}

Keywords: HIV; Cerebral toxoplasmosis; Immune suppression; Neurological symptoms

\section{Introduction}

The clinical symptoms of cerebral toxoplasmosis depend on the localization of the lesions, with an acute or a peracute onset within a few days. The major signs include focal neurological deficits such asparesis, speech problems, or sensory loss. A febrile psychosyndrome with confusion is also a frequent early sign. It is not unusual to see an epileptic seizure as the initial presentation, in the absence of other symptoms [1-6]. Cerebral toxoplasmosis seldom occurs above a CD4 count of 100 cells $/ \mu \mathrm{l}$; over $200 \mathrm{CD} 4$ cells/ $\mu$ it is very rare. To determine the diagnosis, a CT or MRI scan of the head should be performed promptly in each case of a focal neurological deficit $[3,4,6]$. MRI is superior to a CT scan, and almost always shows more visible lesions [4]. A third of the cases have solitary, several (two to five), or multiple (more than five) lesions. In $90 \%$ of the cases, ring enhancement is found around the lesions, often accompanied by edema [1-4]. Up to $97 \%$ of patients with cerebral toxoplasmosis have IgG antibodies. IgM is rarely positive $[1,2]$. The duration of the treatment during the acute stage is at least four weeks. The combination of first choice is sulfadiazine plus pyrimethamine plus leucovorin [7-9]. Another combination of choice is clindamycin plus pyrimethamine plus leucovorin $[7,10]$. The maintenance therapy is the same as the acute therapy but at a half dose and it has to discontinue 6 months after the CD4 T cells count exceeds $200 / \mu \mathrm{l}$. Over the past 5 years, at the AIDS Department of the Specialized Hospital for Infectious and Parasitic Diseases - Sofia, 261 HIV-infected patients have been examined for toxoplasmosis using ELISA tests. 96 of the patients (36\%) had positive IgG antibodies against Toxoplasma gondii. Only two of these patients had clinical symptoms suspicious of cerebral toxoplasmosis. In this article, we present these cases of cerebral toxoplasmosis with different clinical signs: one patient had a stroke-like presentation, while the other had a febrile psychosyndrome.

\section{Case I}

A 35 year old Bulgarian woman was admitted to our department with a one-month history of intermittent fever, headaches, and psychiatric disorders - a persecution mania and aggression. Before being admitted to our Department, she had been treated at a psychiatry department. She did not have seizures, vomiting, or loss of consciousness. She neither drank alcohol, nor did she use any drugs.
The patient had been diagnosed with toxoplasmic lymphadenitis 12 years earlier. The HIV infection had been established 6 years prior to the current admission, but she had denied any monitoring at the AIDS Department and had not received any antiretroviral therapy prior to the current presentation.

On neurologic examination, she had increased tone and brisk reflexes in both the upper and lower extremities and a positive Babinski sign on the left.

The results from the laboratory tests revealed depleted hemoglobin (114 g/l), depleted white blood cell count $(2.4 \mathrm{~g} / \mathrm{l})$ and normal red blood cell and platelet counts. The blood glucose, the liver enzymes, the lipids, and the other biochemical parameters were normal. Her CD4+ count at the moment of admission was 142 cells $/ \mu \mathrm{L}$ and the viral load was 325,000 copies/ $\mu \mathrm{L}$. Toxoplasma IgG was elevated - at $101 \mathrm{UI} / \mathrm{ml}$.

The brain CT scan revealed a rounded ring-enhancing hypodense lesion in the parietooccipital region of the right cortex (Figure 1).

During the acute stage of the disease, the patient was treated for one month with trimetoprim/sulphametoxazole intravenously at the usual dosage $(120 \mathrm{mg} / \mathrm{kg} / \mathrm{d})$ plus clindamycin $3 \times 600 \mathrm{mg}$ i.v. plus acidi folici. During the maintenance stage of the treatment of this patient, we prescribed azithromycin $500 \mathrm{mg} / \mathrm{d}$ orally. We started an ART combination that included 3TC, ABC, and EFV. The patient was discharged after normalization of the psychiatric and neurological status. Two months later, the CD4 T-cell count was elevated to 318 cells/ $\mu \mathrm{l}$, and the viral load was decreased to 158 copies/ $\mu \mathrm{l}$. Three months

*Corresponding author: Nina Yancheva, MD, PhD, AIDS Department, Specialized Hospital for Infectious and Parasitic Diseases, Medical University, Sofia; Bulgaria, Tel: +359 2915 2140; E-mail: dr.yancheva@abv.bg

Received February 20, 2017; Accepted March 04, 2017; Published March 11, 2017

Citation: Yancheva N, Tsvetkova N, Marinova I, Elenkov I, Tchervenyakova T, et al. (2017) A Report of Two Cases with Different Clinical Presentation of Cerebral Toxoplasmosis in HIV-Infected Bulgarian Patients. J AIDS Clin Res 8: 673. doi: 10.4172/2155-6113.1000673

Copyright: (c) 2017 Yancheva N, et al. This is an open-access article distributed under the terms of the Creative Commons Attribution License, which permits unrestricted use, distribution, and reproduction in any medium, provided the original author and source are credited. 


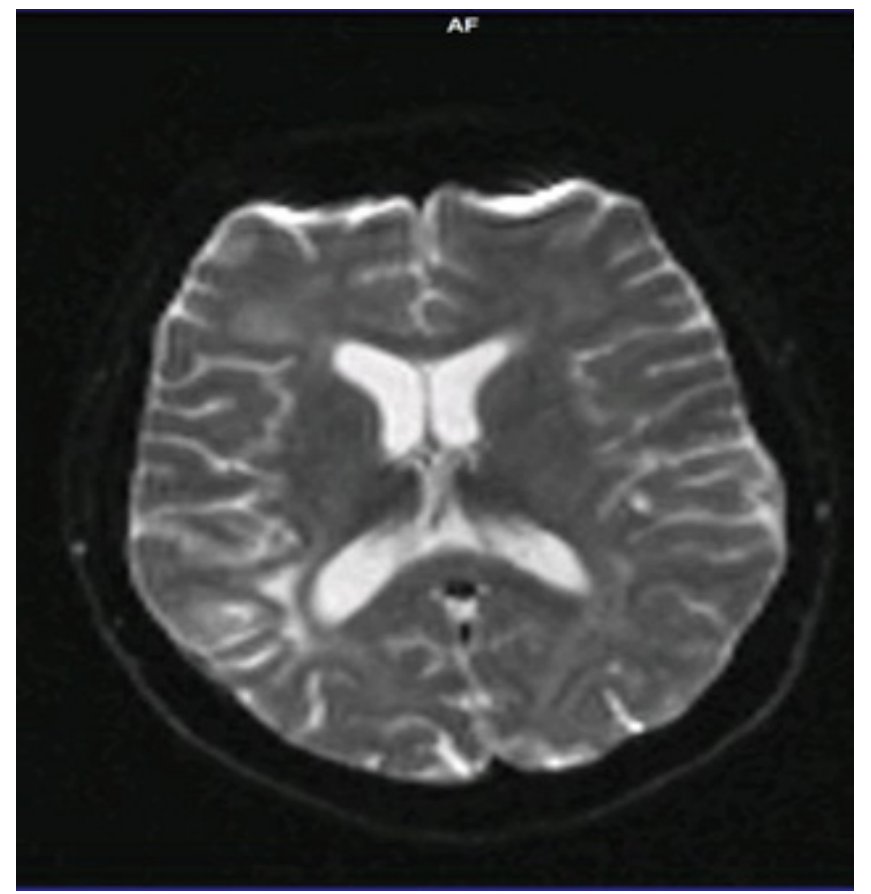

Figure1: Brain CT scan of case I.

after the discharge, the patient denied further HIV monitoring at our Department. She had been influenced by Prof. Duesberg's theory about the HIV infection and refused the antiretroviral treatment. A year later she was readmitted to our Department with a severe immune suppression: a CD4 T-cell count at 42 cells/ $\mu \mathrm{l}$, and clinical and laboratory evidence of disseminated candidiasis and PML and unfortunately, despite the treatment, she died.

\section{Case II}

A 32 year old Bulgarian man was admitted to our Department with a 2 day history of right-sided weakness affecting his leg and arm, and the right half of his face. He had no history of headaches, vomiting or loss of consciousness. He was a smoker, but he did not drink any alcohol or use any drugs. The patient had been diagnosed as HIVpositive approximately 5 years prior to the current admission and had commenced antiretroviral treatment (ART) but had defaulted on it for about 2 years prior to the current presentation. His latest CD4+ count was 79 cells $/ \mu \mathrm{L}$ and his viral load was 101,000 copies $/ \mu \mathrm{L}$.

On neurologic examination, he had right hemiparesis with increased tone and brisk reflexes and up going plantar reflexes (Babinski sign).

The laboratory tests revealed depleted hemoglobin (119 g/l), depleted white blood cell count $(2.9 \mathrm{~g} / \mathrm{l})$ and normal red blood cell and platelet counts. The blood glucose, the liver enzymes, the lipids, and the other biochemical parameters were within reference values. The CD4+ count was very low at 65 cells/ $\mu \mathrm{L}$, and the viral load was 205,357 copies/ $\mu \mathrm{L}$. Toxoplasma IgG was markedly elevated at $221 \mathrm{UI} / \mathrm{ml}$.

A brain CT scan showed one asymmetrical marginally enhancing hypodense lesion in the supratentorial region of the left cortex and one identical lesion in the left hypothalamus, involving the left cerebellar peduncle and the left part of the pons (Figure 2).

During the acute stage of the disease the patient was treated for one month with a triple combination: trimetoprim/sulphametoxazole

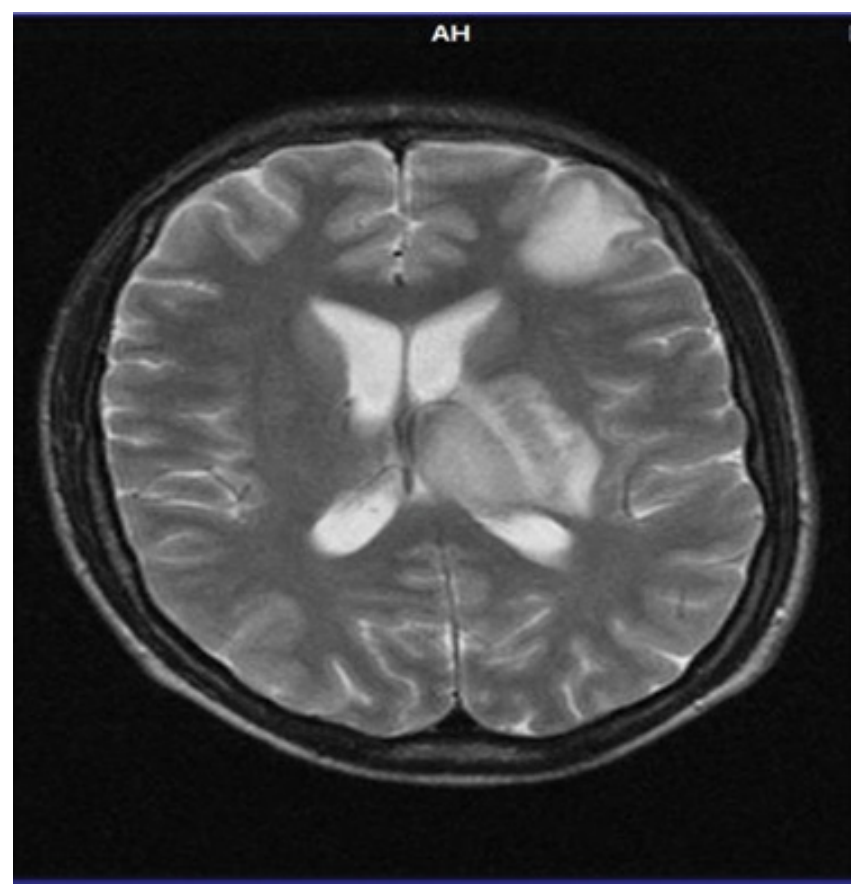

Figure 2: Brain CT scan of case II.

intravenously at the usual dosage $(120 \mathrm{mg} / \mathrm{kg} / \mathrm{d})$ plus clindamycin $3 \times$ $600 \mathrm{mg}$ intravenously plus azithromycin orally at $500 \mathrm{mg} / \mathrm{d}$ plus acidi folici. This unusual therapeutic combination was chosen because of the unavailability of some specific antitoxoplasmic drugs in Bulgaria (namely Pyrimethamine, Sulfadiazine and Rovamycine). During the maintenance stage of the treatment of this patient, we used azithromycin at $500 \mathrm{mg} / \mathrm{d}$ orally for 6 months. We restarted an ART combination that included TDF, FTC and EFV. The patient was discharged after gradually improving muscle power.

The patient's present status regarding his HIV infection is as follows: an undetectable viral load and a CD4 T-cell count at 420 cells/ $\mu \mathrm{L}$. The latest brain CT scan showed significant decrease in the size of the lesions, and the presence of calcifications in them.

\section{Discussion}

Toxoplasmosis is the leading cause of focal central nervous system (CNS) disease in AIDS. CNS toxoplasmosis in HIV-infected patients is usually a late complication of HIV infection and occurs in patients with advanced immune suppression [5]. The prevalence of cerebral toxoplasmosis ranges from $3 \%$ to $50 \%$ [11]. Typically, lesions are found in the brain and their effects dominate the clinical presentation. The disease can occur with different neurological signs and our cases confirmed this. Checking the level of Toxo-IgG in patients with HIV and brain symptoms, and also investigating clinical symptoms in terms of neurological aspects are necessary. In the case of uncertainty, performing CT or MRI in the patients with HIV infection will be helpful. The patients in present report were successfully treated with Cotrimoxazole (trimetoprim-sulfametoxazol) plus clindamycin in the acute stage of the disease.

\section{Conclusion}

HIV-infected patients with severe immune suppression run a higher risk of developing cerebral toxoplasmosis. In the era of HAART, 
Citation: Yancheva N, Tsvetkova N, Marinova I, Elenkov I, Tchervenyakova T, et al. (2017) A Report of Two Cases with Different Clinical Presentation of Cerebral Toxoplasmosis in HIV-Infected Bulgarian Patients. J AIDS Clin Res 8: 673. doi: 10.4172/2155-6113.1000673

this opportunistic infection is comparatively rare. The clinical course of the disease can be with various neurological and psychiatric signs. The therapy against toxoplasmosis at our Department is not the standard one (TMP/SMX plus clindamycin plus azithromycin), but we receive good therapeutic results nevertheless. A positive response to treatment is being judged on the decrease in lesions' size. The patient's good adherence is also crucial to the successful treatment.

\section{References}

1. Porter SB, Sande MA (1992) Toxoplasmosis of the central nervous system in the acquired immunodeficiency syndrome. N Engl J Med 327: 1643-1648.

2. Pott $\mathrm{H}$, Castelo $A$ (2013) Isolated cerebellar toxoplasmosis as a complication of HIV infection. Int J STD AIDS 24: 70-72.

3. Emeka EU, Ogunrin AO, Olubunmi A (2010) Cerebellar toxoplasmosis in HIV/ AIDS: A case report. West Afr J Med 29: 123-126.

4. Sokolska V, Knysz B, Czapiga E, Gasiorowski J, Sasiadek M, et al. (2006) The role of brain magnetic resonance studies in the diagnostics of central nervous system lesions in HIV-1 positive patients. Wiad Lek 59: 805-813.
5. Naqi R, Azeemuddin M, Ahsan H (2010) Cerebral toxoplasmosis in a patient with acquired immunodeficiency syndrome. J Pak Med Assoc 60: 316-318.

6. Ammassari A, Cingolani A, Pezzotti P, De Luca DA, Murri R, et al. (2000) AIDS-related focalbrain lesions in the era of highly active antiretrovira therapy. Neurology 55: 1194-1200.

7. Dannemann B, McCutchan JA, Israelski D, Antoniskis D, Leport C et al. (1992) Treatment of toxoplasmic encephalitis in patients with AIDS: A randomized trial comparing pyrimethamine plus clindamycin to pyrimethamine plus sulfadiazine. Ann Intern Med 116: 33-43.

8. Patil HV, Patil VC, Rajmane V, Raje V (2011) Successful treatment of cerebral toxoplasmosis with cotrimoxazole. Indian J Sex Transm Dis 32: 44-46.

9. Torre D, Speranza F, Martegani R, Zeroli C, Banfi M, et al. (1998) A retrospective study of treatment of cerebral toxoplasmosis in AIDS patients with trimethoprimsulphamethoxazole. J Infect 17: 15-18.

10. Yapar N, Erdenizmenli M, Oğuz VA, Cakir N, Yüce A (2005) Cerebral toxoplasmosis treated with clindamycin alone in an HIV-positive patient allergic to sulfonamides. Int J Infect Dis 9: 64-66.

11. Taila AK, Hingwe AS, Johnson LE (2011) Toxoplasmosis in a patient who was immunocompetent: A case report. J Med Case Rep 5: 16. 